\title{
Forecast of precipitation for the 1994 flood in Piedmont: performance of an ensemble system at convection-permitting resolution
}

\author{
I. M. L. Cerenzia ${ }^{1}$ • G. Pincini ${ }^{1} \cdot$ T. Paccagnella ${ }^{1} \cdot$ E. Minguzzi ${ }^{1} \cdot$ T. Gastaldo $^{1} \cdot$ V. Poli $^{1}$ • \\ M. S. Tesini ${ }^{1} \cdot$ P. Patruno ${ }^{1} \cdot$ D. Cesari ${ }^{1}$
}

Received: 24 April 2020 / Accepted: 24 November 2020/ Published online: 10 December 2020

(C) The Author(s) 2020

\begin{abstract}
The major flood that affected the Piedmont region in Italy in November 1994 is reforecast after 25 years in ensemble mode at the convection-permitting resolution of $2.2 \mathrm{~km}$ using the regional model COSMO. The performance of the probabilistic forecast of precipitation is assessed against rain-gauge observations, also in comparison with the driver system, i.e., the probabilistic re-forecast produced by ECMWF based on the operational IFS (Cycle 46r1) at grid spacings of $18 \mathrm{~km}$. The convection-allowing system dynamically downscales the ECMWF ensemble and includes an explicit treatment of deep convection. Results indicate that both systems can predict up to 4 days in advance the timing and the spatial patterns of the precipitation, although with higher confidence for the convection-resolving system. The benefit of high resolution is shown mainly in the prediction of intense precipitation and in terms of correct amounts and locations, and confidence of occurrence (at day 3, the estimated probability of exceedance of $200 \mathrm{~mm}$ was higher than $90 \%$ over areas actually hit by such rainfall amounts). Additionally, convection-permitting resolution improves the representation of orographic precipitation, reducing the upwind precipitation displacement typical of coarser models and including the possible development of strong convection episodes embedded in the large-scaleforced orographic rise. For the high-resolution ensemble, the spread indicates large uncertainty at the local scale, mainly in defining the flow tendency to flank or flow over each mountain.
\end{abstract}

Keywords Convection-permitting model $\cdot$ Ensemble $\cdot$ High-resolution $\cdot$ Reforecast $\cdot$ Flood

I. M. L. Cerenzia

icerenzia@arpae.it

1 ARPAE-Emilia Romagna, Bologna, Italy 


\section{Introduction}

In the first few days of November 1994, a major flood invested the Piedmont region, in northwest Italy. From late 4 November to early 6 November, heavy rainfall affected a vast area of Piedmont, with observed precipitation exceeding $200 \mathrm{~mm} /$ day at various rain gauges (Buzzi et al. 1998; Luino 1999). A first maximum of precipitation affected the northwest sector of the Alps and a second was located over south Piedmont (Maritime Alps). Rainfalls produced exceptional river discharges and associated floods. They caused 77 casualties and extensive damages to infrastructure and agriculture. From a meteorological point of view, it was a complex flood-producing rainfall episode, activated by well-predictable large-scale forcings, and in which the small-scale interaction between the mesoscale flow and the topography played a major role in triggering the more severe precipitation events.

In the following years, several studies considered this extreme event as a test case to assess the performance of different forecasting systems (Petroliagis et al. 1997, Marsigli et al. 2001, Cassardo et al. 2002, Ferraris et al. 2002). Ensemble Probabilistic Systems (EPS) were particularly investigated, to exploit their capability of predicting the risk of extreme flooding events over a localized region at longer time ranges ( 3 or more days ahead) and to anticipate the issue of alerts to the population (Petroliagis et al. 1997, Marsigli et al. 2001, Ferraris et al. 2002).

In 1994, the European Centre for Medium-Range Weather Forecast (ECMWF) had already implemented (since 2 years) an EPS (Molteni et al. 1996; Buizza et al. 1999), which was used to estimate the degree of confidence associated with a deterministic higher-resolution prediction. At that time, ECMWF was using a probabilistic system based on 32 perturbed members plus one unperturbed run (control). Perturbed initial conditions were created by using the singular vector method (Molteni et al. 1996). The EPS was running with a horizontal resolution of $320 \mathrm{~km}$ and 19 vertical levels. Despite the coarse resolution, in the case of the Piedmont flood of 1994, the ECMWF probabilistic system reported a clear warning of severe weather over northwestern Italy already 5 days ahead, with increasing confidence on the localization with the approaching of the event (Petroliagis et al. 1997). Nevertheless, none of the members was able to forecast the intensity of precipitation due to the low resolution of the integration.

A dynamical downscaling of the ECMWF EPS for this event was performed few years later by Marsigli et al. (2001), using the Limited area Ensemble Prediction System (LEPS), based on the limited area model LAMBO (Limited Area Model BOlogna) at a horizontal resolution of about $20 \mathrm{~km}$ (Marsigli et al. 2001; Montani et al. 2001; Montani et al. 2003). It consisted of 5 members, with initial and boundary conditions provided by 5 selected members of the ECMWF EPS, chosen using an ad hoc cluster analysis technique (Montani et al. 2001). Compared to ECMWF EPS, the LEPS resulted more capable of capturing the general structure of the precipitation field, showing a double-peak structure in the probability values with maxima over northern and southern Piedmont. However, the second maximum was misplaced by about $50 \mathrm{~km}$. Moreover, the LEPS probability of precipitation exceeding $100 \mathrm{~mm} /$ day was only moderate (50-60\%) in regions affected by the heaviest rainfall (larger than $200 \mathrm{~mm} /$ day). Therefore, while being able to better resolve those orographic and mesoscale processes responsible for heavy precipitation events, the LEPS showed a large uncertainty in the localization and an underestimation of the intensity of precipitation. Such large uncertainty would have substantially affected the downstream hydrological modeling during this event, preventing the correct representation of the river discharge on the mountain basins, as demonstrated by Ferraris et al. (2002). 
In recent years, the increased availability of computer resources has made more expensive approaches feasible. For very short-range forecasts ( 0 to $6 \mathrm{~h}$ ), numerous studies have been and are being carried out to improve forecasting using radar data. Blending of fields extrapolated from radar observations and forecasts from numerical weather models is one of the most widely used techniques to combine short-term extrapolation of observations with numerical forecasts to produce a 0-6 h nowcasting forecast (Golding 1998; Pierce et al. 2001; Wong et al. 2009; Atencia et al. 2010; Haiden et al. 2011; Bowler et al. 2006; Nerini et al. 2019). These techniques allow for the limiting of the spin-up problems of numerical models, achieving a continuous transition at the critical period around 1-3 $\mathrm{h}$, when the accuracy of forecasting with extrapolation methods is drastically reduced. However, the prediction of very short ranges is out of the scope of the present paper, which is instead dedicated to the probabilistic forecast of medium-range weather. Indeed, for forecast ranges from a few hours to a few days, ensemble prediction systems at very high resolution are now commonly used.

Modern global ensemble systems operate at national weather centers in Canada, Germany, and the UK, and at ECMWF at grid points separated by tens of kilometers. At the regional scale, limited-area models (LAMs) reach finer resolutions and in the recent years convectionpermitting ensemble prediction systems with grid spacing commonly between 1 and $4 \mathrm{~km}$ have been developed by several weather services (Klasa et al. 2018; Marsigli 2020; Hagelin et al. 2017; Frogner et al. 2019; Bouttier et al. 2012).

In this study, the re-forecast of the major flood of Piedmont of 1994 is performed by a convection-permitting ensemble based on the COSMO model (Schaettler et al. 2019), which downscales the operational ECMWF EPS (Palmer 2019). Their performances are compared in order to assess to what extent it is advantageous to run a convection-permitting limited-area ensemble over a convection-parametrizing global EPS in a similar complex flooding event.

So far, convection-allowing ensemble systems were found to enhance the quality of the predicted spatial patterns of precipitation, especially regarding the location and timing of precipitation (Klasa et al. 2018, Iyer et al. 2016, Bouttier et al. 2012; Le et al. 2013, Hohenegger et al. 2008). The superior performance of the convection-allowing ensembles resulted in part from the lower error and in part from the larger growth rates of spread, associated with the representation of smaller scale, which enhances the skill-spread ratio (Clark et al. 2010; Klasa et al. 2018). The benefit of convection-resolving ensembles in terms of precipitation forecast resulted strongly case-dependent. It was shown that the added value varies between seasons, lead times, and synoptic situation (Frogner et al. 2019, Klasa et al. 2018, Hagelin et al. 2017, Hohenegger et al. 2008). It resulted higher in summer compared to winter (due to the higher frequency of convective events), for shorter lead times compared to longer lead times (due to the degradation of the predictability of smaller scales with the lead time, Frogner et al. 2019, Surcel et al. 2015), for daily convective precipitation compared to precipitation events dominated by large-scale advection (due to the improved representation of the local-scale triggered events and the diurnal cycle of precipitation, Klasa et al. 2018, Clark et al. 2010, Iyer et al. 2016). Regarding the last point, Klasa et al. (2018) found nevertheless that the precipitation forecasts were still enhanced for events dominated by large-scale forcings, pointing to the importance of the interaction of the mesoscale flow with the topography in triggering these processes. Finally, convection-allowing ensembles showed higher-quality predictions of severe precipitation events, while the opposite was true for light rain forecast (Iyer et al. 2016; Le et al. 2013), due to the underestimation of the frequency of intense precipitation events by coarse-resolution systems and of low rain events by high-resolution EPS. 
On this basis, in the re-forecast of this major flood, a benefit from the convection-resolving EPS system over the convection-parametrizing one is expected. This investigation aims at assessing to which degree the convection-allowing system can add value to the precipitation forecast, especially regarding the predictability of the heaviest rainfall and of those local-scale precipitation patterns that are influenced by the presence of complex terrain. This analysis is relevant in order to justify the cost of running an expensive high-resolution ensemble system and to evaluate the benefit of developing specific probabilistic tools for the early-warning system for the local scale. One event is obviously not sufficient to provide reliable statistical validation. Therefore, this study may be viewed as a pilot investigation highlighting the possible strengths and weaknesses of a convection-permitting EPS compared to its global-scale driver.

A detailed description of the ensemble systems used for this experiment is in Section 2. In the same section, a report of this severe weather event and of the observational dataset is present. The predictability capacity of the convection-permitting COSMO ensemble compared to the global ECMWF EPS is investigated in Section 3. Issues related to the correct spatiotemporal localization of precipitation maxima, the interaction with small-scale orographic features, and the ensemble uncertainty are also discussed.

\section{Methods and data}

\subsection{Ensemble probabilistic system at convection-permitting resolution}

The COSMO model is a non-hydrostatic limited-area atmospheric prediction model (www. cosmo-model.org) designed to allow numerical weather prediction models to represent atmospheric processes and phenomena down to meso- $\beta(20-200 \mathrm{~km})$ and meso- $\gamma(2-$ $20 \mathrm{~km}$ ) scales. The COSMO model is based on the primitive thermo-hydrodynamical equations describing compressible flow in a moist atmosphere, with a variety of physical processes taken into account by parameterization schemes (Schaettler et al. 2019). The COSMO model has been run operationally since 1999 at ARPAE-Emilia Romagna and in several national weather services in Europe. For operational aims, it is run at horizontal resolutions ranging from 1.1 to $7 \mathrm{~km}$ in deterministic mode and from 2.2 to $7 \mathrm{~km}$ in ensemble mode (http://www. cosmo-model.org/content/tasks/operational/default.htm).

The ensemble probabilistic system at high resolution, referred to as COSMO-2I-EPS, has been developed at ARPAE-Emilia Romagna in 2016. At the time of writing, it runs in pre-operational mode and it is initialized once a day at $00 \mathrm{UTC}$ with a forecast range of $48 \mathrm{~h}$. COSMO-2I-EPS consists of 20 members that receive the initial conditions, including the soil moisture and sea surface temperature perturbations, from the 20 perturbed analyses of the KENDA LETKF (Local Ensemble Transform Kalman Filter) system (Schraff et al. 2016). The assimilation system applied to initialize COSMO-2I-EPS is extensively described in Gastaldo et al. (2018). The boundary conditions are taken from the first 20 members of the COSMO-ME-EPS (Marcucci et al. 2014), a COSMO-based ensemble system at $7 \mathrm{~km}$ horizontal resolution, developed at COMET (Operational Centre for the Meteorology of the Italian Air Force). The initial conditions for COSMO-ME-EPS are derived from a LETKF system (Bonavita et al. 2010), while the lateral boundary conditions are from the ECMWF EPS (Palmer 2019). The pre-operational domain of COSMO-2I-EPS covers the Italian territory and the surrounding seas with a 2.2-km horizontal resolution and 65 vertical levels (domain reported in Fig. 2(a)). Targeted products, like probability maps with thresholds, are implemented, in particular for thunderstorms and convective precipitation events. 
For the specific purpose of the 1994 Piedmont flood re-forecast, a simplified version of COSMO-2I-EPS has been used. Due to the unavailability of the intermediate resolution ensemble system COSMO-ME-EPS, the initial and boundary conditions for the members of COSMO-2I-EPS are taken directly from the ECMWF EPS members and no data assimilation procedure is applied at the $2.2 \mathrm{~km}$ scale. Therefore, in this experiment, COSMO-2I-EPS neither benefits from the perturbation of the initial conditions at its resolution scale nor makes use of perturbed boundary conditions produced by a COSMO-based ensemble at intermediate resolution, while merely it performs a dynamical downscaling of the ECMWF ensemble to a convection-permitting resolution.

The ECMWF performed an ensemble re-forecast of this event based on the operational Integrated Forecasting System (IFS Cycle 46r1) at grid spacings of $18 \mathrm{~km}$ and 91 vertical levels (hereafter referred to as ENS). ENS contains 51 members, an unperturbed control forecast and 50 forecasts with independently perturbed initial conditions. The unperturbed initial condition is taken from the ERA5 global reanalysis (Hersbach et al. 2020), while an Ensemble Data Assimilation technique is applied to perturb the re-forecast initial condition (Vitart et al. 2009). The model perturbations are supplied by the Stochastically Perturbed Parameterisation Tendencies Scheme (Buizza et al. 1999; Leutbecher et al. 2017).

For the reconstruction of this Piedmont major flood, the integrations of ENS and of its dynamical downscaling COSMO-2I-EPS started on 3 November 1994 at 00 UTC and they lasted for 5 days. In this experiment, the ensemble size of COSMO-2I-EPS has been increased to 50 members, in order to downscale all the ENS members. A list of the main technical characteristics of the ensemble probabilistic systems used for this investigation is reported in Table 1.

\subsection{Description of the case study}

\subsubsection{Synoptic situation}

The meteorological situation was typically autumnal, favorable to the development of intense rainfall on the Italian northwest. Such weather patterns are not uncommon in the Italian climatology of the autumn period; however, the exceptional nature of this event was made possible by the persistence of the same circulation for several days.

Table 1 Main technical features of ECMWF ENS and COSMO-2I-EPS in their experimental versions

\begin{tabular}{lll}
\hline Main technical feature & \multicolumn{2}{l}{ Ensemble system } \\
\cline { 2 - 3 } & ECMWFENS & COSMO-21-EPS \\
\hline Mesh size & $0.16^{\circ}$ & $0.02^{\circ}$ \\
Horizontal resolution & $18 \mathrm{~km}$ & $2.2 \mathrm{~km}$ \\
Vertical resolution & $91 \mathrm{lev}$ & $65 \mathrm{lev}$ \\
Type of model & Hydrostatic & Non-hydrostatic \\
Type of deep convection & Parameterized (Bechtold et al. 2014) & Explicit \\
Initial conditions & ERA5/EDA & ECMWF ENS members \\
Boundary conditions & - & ECMWF ENS members \\
Model perturbation & Stochastic scheme & - \\
Forecast range (h) & 120 & 120 \\
Ensemble size & 50 & 50 \\
Starting times (UTC) & 3 Nov 1994 00 UTC & 3 Nov 1994 00 UTC \\
\hline
\end{tabular}


Starting from 3 November 1994, the motion of the air masses on the European continent changed from zonality to having a marked meridional component. Therefore, the strong jet stream that previously flowed across the 50th parallel took on a meandering shape. The consequent slowdown of the jet stream led to the establishment of a blocking pattern. The downward undulation of the jet stream hosted a trough over western Europe, while a blocking anticyclone formed at the crest of the wave over eastern Europe (Tibaldi et al. 1997). This blocking situation is clearly visible from the mean sea level pressure (MSLP) and $500 \mathrm{hPa}$ geopotential height fields as shown in Fig. 1 for 4 November (a), 5 November (b), and 6 November 1994 (c).

Considering the precipitation over the 5 days of flooding event from 3 November to 7 November 1994, the rain gauge network recorded precipitation peaks over $500 \mathrm{~mm}$ on the Alpine region on the northwest Torino Province and over $300 \mathrm{~mm}$ on the Apennines area between Cuneo and Savona provinces (see Figs. 2 and 3). The rainiest days of the event were 4, 5, and 6 November 1994 (see Fig. 4). On day 4, there was an intensification of geopotential gradient and of southerly flow on the eastern side of the trough (Buzzi et al. 1998). This mass of warm and humid air was then directed towards the northwest of Italy, where it was raised orographically firstly by the Maritimes Alps and Ligurian Apennines and secondly by the Western Alps (Fig. 2), producing large quantities of rain. In this day, the most affected area was the first orographic barrier. In fact, on the Savona area, a quasi-stationary meso- $\beta$ convective system likely has occurred. Although regional radar and satellite imagery frequently reveal these stationary or backward regenerative systems that assume a characteristic $\mathrm{V}$ shape (Delrieu et al. 2005), in this case, it was not possible to have these images available. Nevertheless, the pattern and intensity of precipitation recorded by the rain gauge network led us to suppose similar phenomena developed (see Fig. 4). In this type of thunderstorm, new convective cells continually regenerate at approximately the same rate at which the older ones are advected away (Chappell 1986). The severity of these events can be tightly dependent on local factors, such as complex coastlines and steep orography, so that even very-small-scale (e.g., a few kilometers) features need to be considered. To improve prediction capabilities, progress must be made in understanding the mechanisms that govern the precise location of the precipitation system as well as of those that can occasionally produce uncommon amounts of precipitation (Ricard et al. 2012). These types of severe convective systems are frequent in Liguria and are established on the convergence between different air masses: the warm and moist one from the Mediterranean Sea and the cold one from the Po Valley flowing down from the Ligurian Apennine passes. This convergence line is caused by a pressure low that usually forms over the Ligurian Sea downwind of the Apennines and is able to activate deep

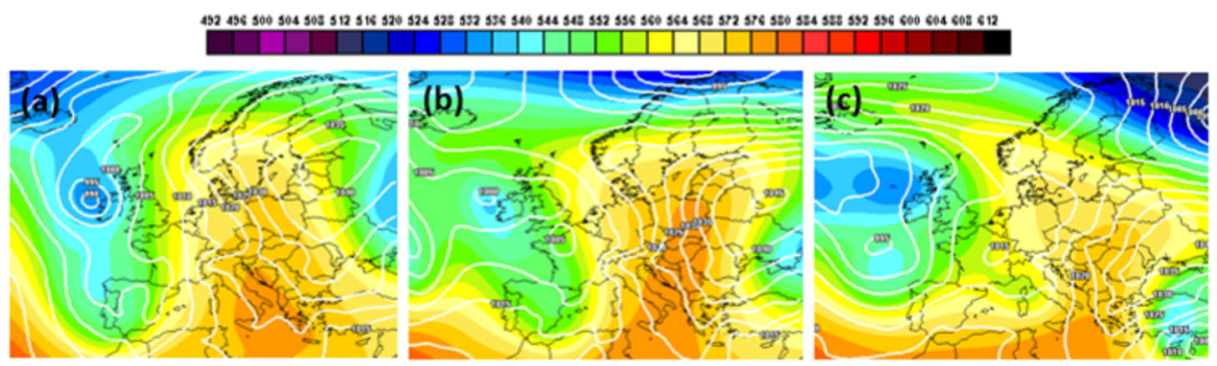

Fig. 1 Geopotential at $500 \mathrm{hPa}$ in colors and white isobars of MSLP for 4 November 1994 12UTC (a), 5 November 1994 12UTC (b), and 6 November 1994 12UTC (c) from ERA5 (source Meteociel) 


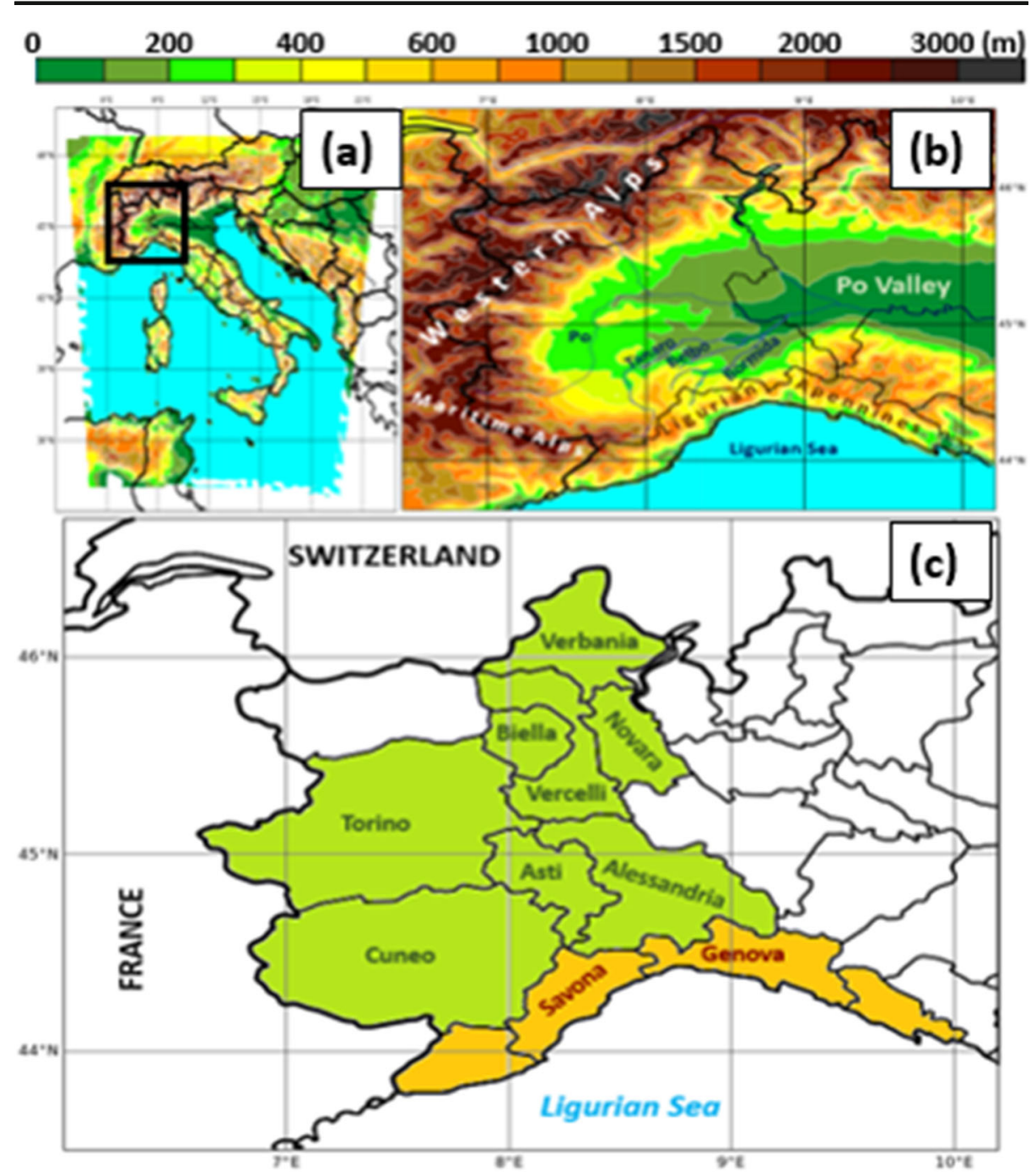

Fig. 2 COSMO-2I-EPS operational domain with the area under study (the northwest of Italy, the Ligurian Sea, and neighboring countries) highlighted by the black frame (a). Geographical and political toponyms of this area are indicated respectively in (b) and (c), where green-colored provinces belong to the Piedmont region and brown-colored ones belong to the Liguria region

convection, capable of producing intense thunderstorms, though often small-sized, that repeatedly impacts the same area for several hours (Fiori et al. 2014). This is probably the situation that developed on the Savona area, where on the evening of 4 November a station had recorded $135 \mathrm{~mm}$ in $4 \mathrm{~h}$. This area pertains to the drainage basins of the Tanaro, Bormida, and Belbo rivers (Fig. 2(b)), which caused severe and disrupting floods during 5-6 November.

Day 5 was the rainiest because of the intensification of the southerly flow and its deflection to the west when approaching the Western Alps. As a result, the heaviest rainfall was observed over the eastern flank of the Western Alps, north of Torino, affecting the watersheds of different river tributaries of the Po River. However, in this second area, flooding was of limited extent, partly because of the lowering of the freezing level to about $2000 \mathrm{~m}$ above sea level 


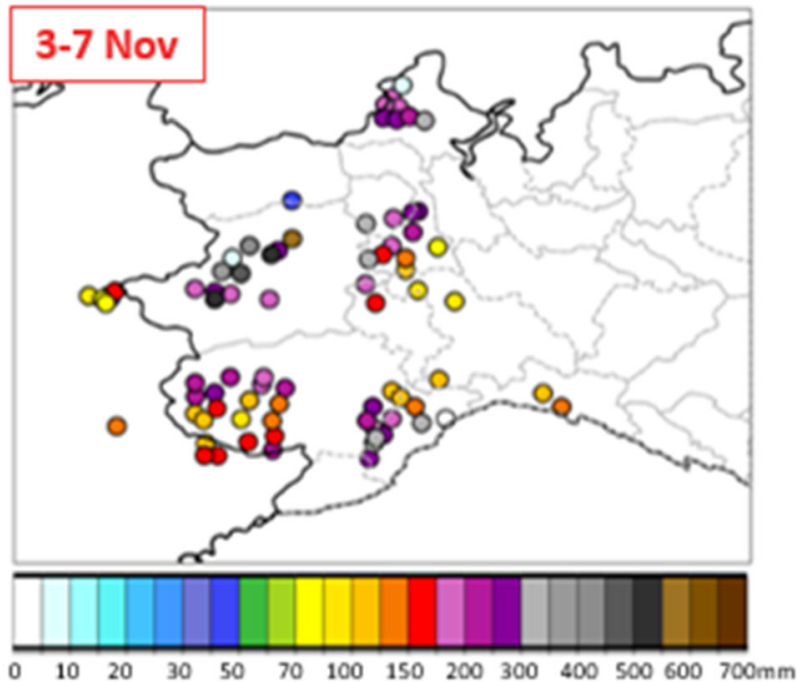

Fig. 3 Total precipitation recorded by the network of rain gauges over the 5 days of flooding event from 3 November to 7 November 1994 (data kindly provided by ARPA Piemonte)

(mountain peaks reach $3000 \mathrm{~m}$ in this area) and partly because the rainfall was more uniformly distributed in time over a period of about $24 \mathrm{~h}$ (Buzzi et al. 1998).

The first hours of day 6 were characterized by the same type of circulation as day 5 , with most of the precipitation in the same areas. Subsequently, the passage of the cold front interrupted the flow of warm humid air from the Mediterranean Sea and precipitation progressively decreased.

\subsection{Observational dataset}

The verification domain was selected in such a way as to include the entire Piedmont territory, but also other adjacent regions where it rained heavily such as Liguria and southeastern France. This verification area, included in the domain of both ensemble systems used, has the following geographic coordinates as borders: latitude $43.50 \mathrm{~N}-46.70 \mathrm{~N}$, longitude $6.00 \mathrm{E}-$ 10.20 E. Only direct observations within the domain were considered. The dataset used consists of 75 rain gauges distributed in the selected verification domain and grouped mainly

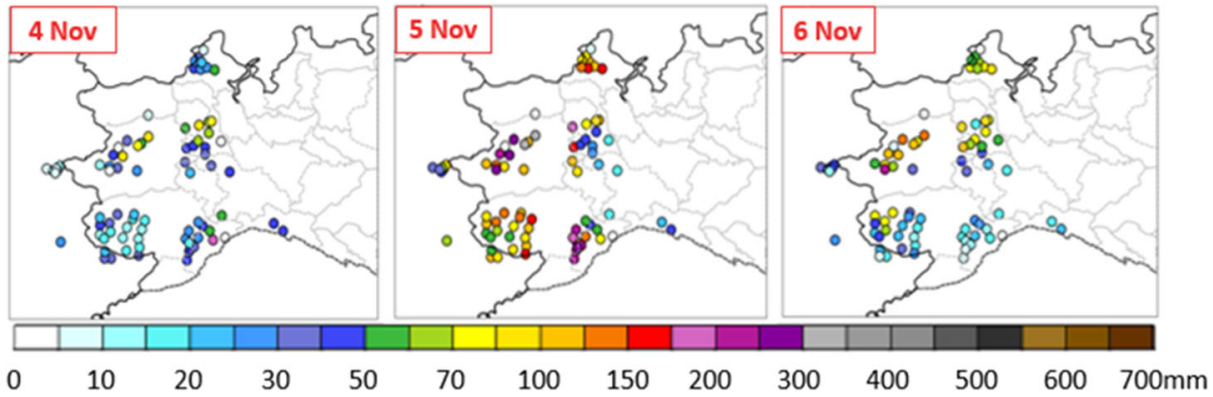

Fig. 4 Daily precipitation collected by the network of rain gauges for 4, 5, and 6 November 1994 (data kindly provided by ARPA Piemonte) 
in five sectors that cover the areas mostly affected by the heaviest precipitation (Fig. 3). As mentioned in the previous paragraph, the observational dataset covers 5 days, from 3 November at 00 UTC to 8 November at 00 UTC, and it fully includes the flood event. The data coming from the station network used in the evaluation procedure were made available by Arpa Piemonte.

\section{Results}

\subsection{Probability of occurrence}

The probability maps are one of the most commonly used products to assess the ensemble confidence in predicting the occurrence of an event. In the case of precipitation events, the probability map of exceedance of a certain precipitation threshold is useful to indicate the areas affected by a specific intensity of rainfall or higher and the associated degree of reliance.

On 4 November, both the ensemble systems ENS and COSMO-2I-EPS forecast the observed double peaks of maximum precipitation, over the northwest sector of Piedmont Alps and over the Maritime Alps between Liguria and Piedmont (Fig. 5). The ensemble systems are almost certain to locate the most intense rainfall in these areas with an interval of probability 90-100\% for precipitation higher than $40 \mathrm{~mm}$. The same signal is present also for precipitation larger than $70 \mathrm{~mm}$, although with lower confidence. For both the ensembles, the match with the observations recorded by the rain gauges is very good, as all the records that exceed the precipitation threshold fall in or in the vicinity of the colored area (indicating probability larger than $10 \%)$ for all the considered precipitation thresholds $(20 \mathrm{~mm} /$ day, $40 \mathrm{~mm} /$ day, $70 \mathrm{~mm} /$ day). COSMO-2I-EPS represents the exceedance of 40 and $70 \mathrm{~mm} /$ day over more extended areas and with higher confidence compared to ENS. The probability maps for $40 \mathrm{~mm} /$ day and $70 \mathrm{~mm} /$ day show a precipitation field elongated over the northern part of Torino Province, correctly matching the observed precipitation, and over the Verbania Province, where instead the foreseen intensity is slightly overestimated (values larger than $40 \mathrm{~mm}$ were recorded only
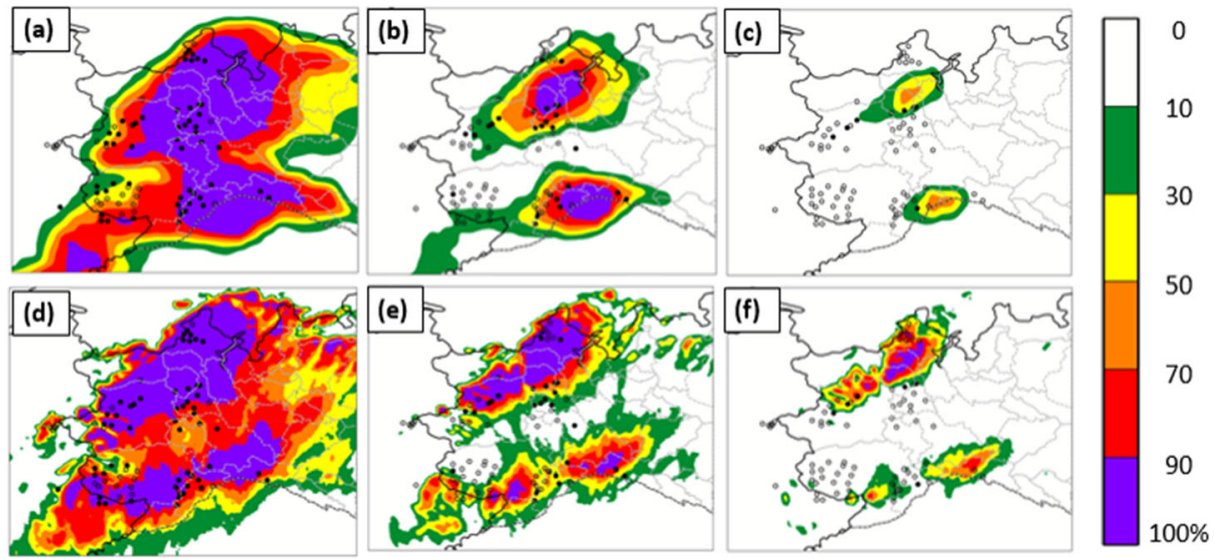

Fig. 5 Probabilistic maps of daily accumulated precipitation for 4 November 1994: colors indicate the probability of precipitation exceeding the threshold of $20 \mathrm{~mm}(\mathrm{a}, \mathrm{d}), 40 \mathrm{~mm}(\mathrm{~b}, \mathrm{e})$, and $70 \mathrm{~mm}(\mathrm{c}, \mathrm{f})$; the first line refers to ECMWF ENS forecasts, the second to COSMO-2I-EPS ones. The rain gauge stations indicated by the black dots are those for which the threshold was exceeded, while non-exceedance cases are indicated by empty dots 
in few stations and all observations were lower than $70 \mathrm{~mm}$ ). Regarding the peak of precipitation observed between Piedmont and Liguria, COSMO-2I-EPS distributes the precipitation along the southwest-northeast axis in correspondence with the mountains' axis, while ENS shows the maximum over the gulf of Genova, partially offshore. It is worthy to remark that the precipitation on 4 November was mainly due to the orographic lift of the southerly flow and in this region it affected the Maritime Alps and Ligurian Apennines. The tendency to start the orographic lift too far upstream shown by ENS is a common error of coarse-resolution models due to the topography smoothing and to the lack of any drift of the convective cells when the deep convection is parametrized (Richard et al. 2007; Smith et al. 2015).

Similar considerations are valid also for 5 November, when the most intense precipitation was recorded. Both probabilistic systems are able to forecast with high confidence the moderate precipitation diffused over the entire Piedmont region, which was mainly of stratiform origin (Fig. 6 for thresholds $20 \mathrm{~mm} /$ day and $40 \mathrm{~mm} /$ day). Values larger than $70 \mathrm{~mm} /$ day and $100 \mathrm{~mm} /$ day over the northwest sector of the Alps and over the Maritime Alps are correctly located by both EPS, although COSMO-2IEPS presents a higher agreement with the observations with larger confidence (Figs. 6 and 7). For precipitation thresholds of $150 \mathrm{~mm} /$ day and $200 \mathrm{~mm}$ /day, COSMO-2I-EPS continues to forecast the occurrence with high probability (90-100\%), while ENS reports gradually lower probability with the threshold increment and almost no cases of precipitation higher than $200 \mathrm{~mm} /$ day. In general, COSMO-2I-EPS shows a very good agreement with the surface observations, especially for precipitation thresholds equal to $70 \mathrm{~mm} /$ day and larger, up to $200 \mathrm{~mm} /$ day. The probability of precipitation larger than $200 \mathrm{~mm} /$ day is between 90 and 100\% in the areas actually affected by such heavy rainfall, demonstrating the greater capacity of the convection-permitting system to represent the most intense phenomena. At the same time, the number of false alarms and missed events is low even at this threshold (the range of probability 90-100\% reports 6 hits, 1 false alarm, and 4 missed events), pointing out the accuracy in localizing the convection occurrence.

As reported in Section 2.2, in the first hours of 6 November, the low-level flow wedged in the Po Valley, blowing from southeast to northwest, and a surface low pressure formed over
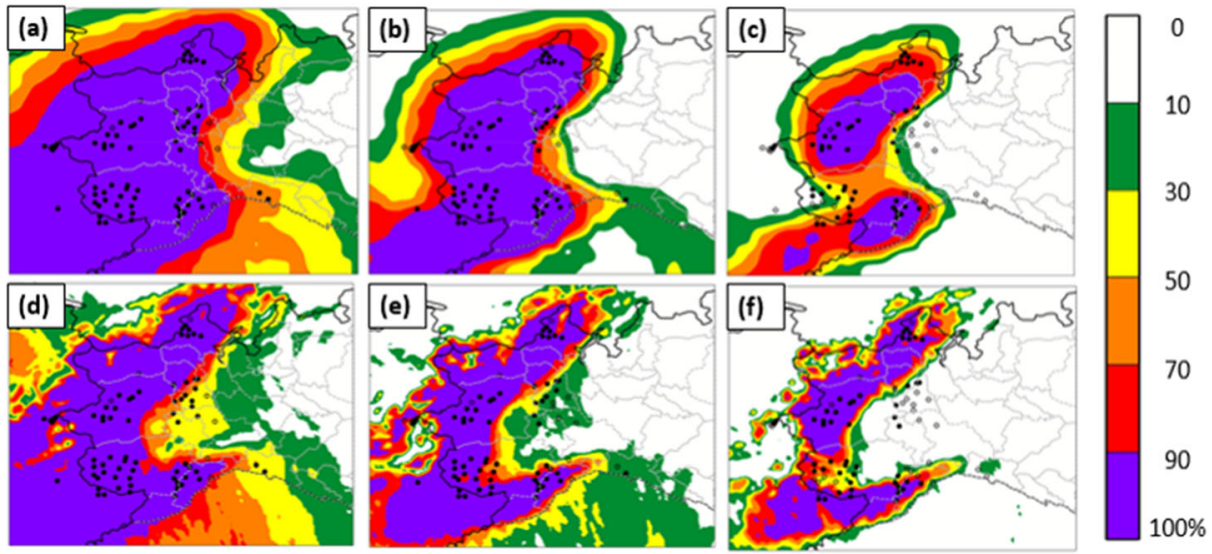

Fig. 6 As in Fig. 5, but for 5 November 1994 

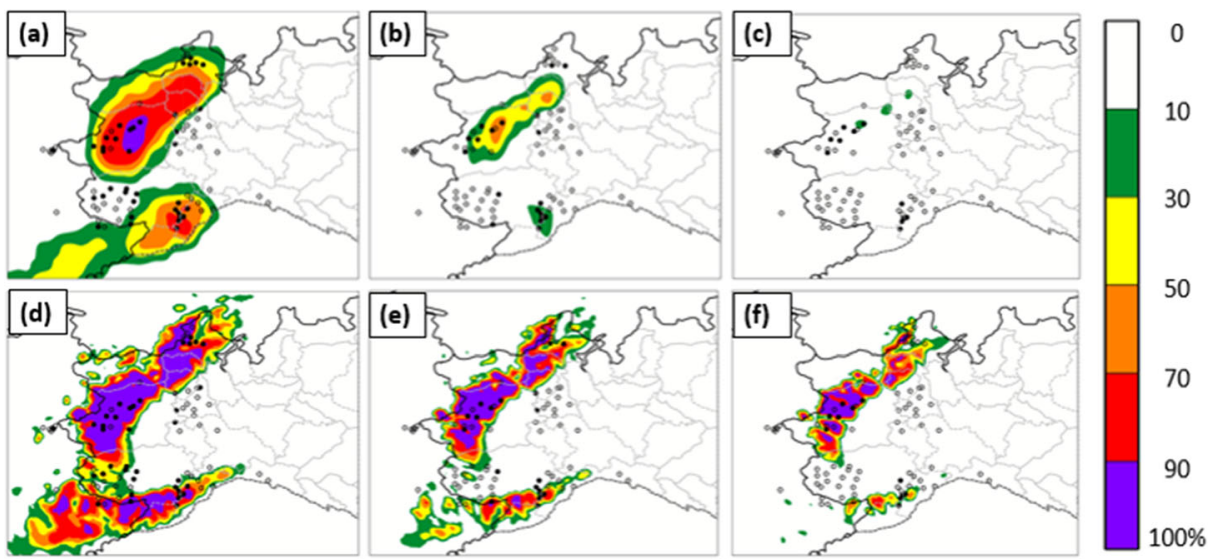

Fig. 7 Probabilistic maps of daily accumulated precipitation for 5 November 1994: colors indicate the probability of precipitation exceeding the threshold of $100 \mathrm{~mm}(\mathrm{a}, \mathrm{d}), 150 \mathrm{~mm}$ (b, e), and $200 \mathrm{~mm}$ (c, f); the first line refers to ECMWF ENS forecasts, the second to COSMO-2I-EPS ones. The rain gauge stations indicated by the filled dots are those for which the threshold was exceeded, while non-exceedance cases are indicated by empty dots

the southern Piedmont region. Afterwards, the passage of the cold front interrupted the flow of warm humid air and the precipitation gradually ceased. The intensity of the zonal wind component and the position of the surface minimum pressure were the most relevant features that could help in identifying the areas affected by precipitation. COSMO-2I-EPS forecasts the heaviest rainfall over the north and northwest Alpine sectors of Piedmont, with a great agreement against the surface observations. The ECMWF ensemble produces a similar prediction of the precipitation pattern, although confidence is low over the northwest Alps sector, which was instead affected by intense precipitation. As it will be described later (Section 3.3), ENS presents a large uncertainty in the zonal intensity of the low-level wind in the Po Valley, which was responsible for the orographic precipitation over the northwest part of the Alpine ridge (Fig. 8).
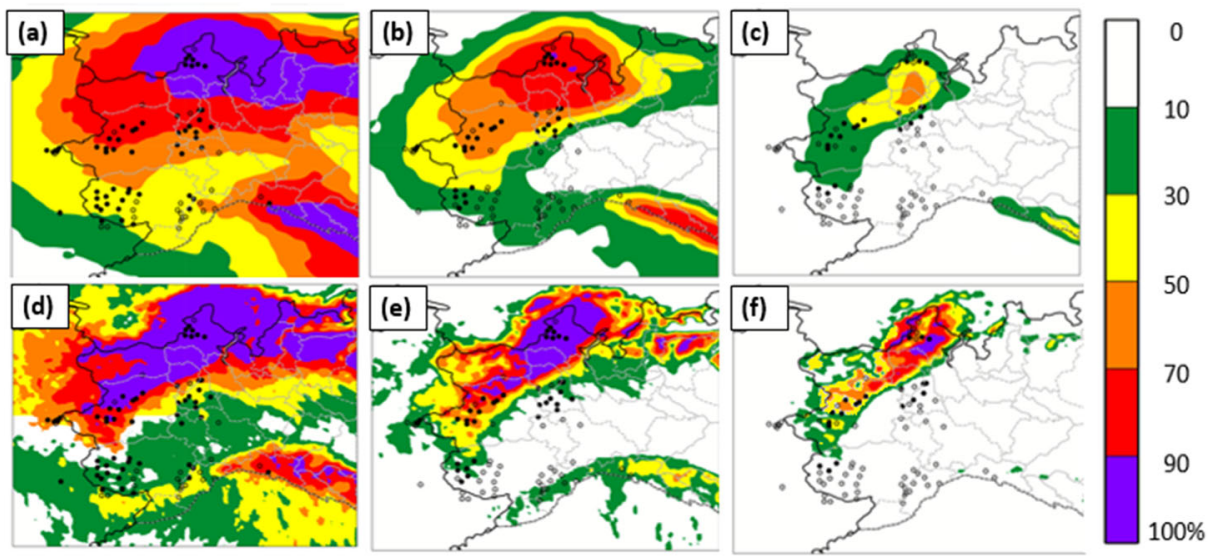

Fig. 8 As in Fig. 5, but for 6 November 1994 


\subsection{Ensemble mean}

Figure 9 reports the maps of the ensemble mean for the Piedmont flood probabilistic reforecasts. The ensemble mean averages out the scales for which the system is less confident; thus, it indicates the most predictable elements of the forecast. The precipitation spatial patterns of COSMO-2I-EPS depicted by the ensemble mean are coherent with those of the probability maps, and as already discussed, they turned out to be very accurate. If the intensity of precipitation is taken into account, COSMO-2I-EPS results able to represent the extreme values of the observed intensity of precipitation, with the highest values on 5 November over the northwest Alpine bow (maximum of $512 \mathrm{~mm} /$ day) and a secondary maximum over the Maritime Alps (maximum of $267 \mathrm{~mm} /$ day). Similar amounts were recorded in these areas. Nevertheless, it is important to underline that some members produce higher peak values (up to $730 \mathrm{~mm} /$ day), while others predict lower amounts (down to $480 \mathrm{~mm} /$ day). When comparing these predictions with those of ENS, the added value of a high-resolution convection-permitting system is evident. Due to coarse resolution, the ensemble mean of ENS predicts smoothed precipitation fields with maximum values at least 50\% lower than COSMO-2I-EPS and the observations. On 5 November, the maximum daily accumulated amount is $151 \mathrm{~mm} /$ day over northwest Piedmont and the secondary maximum over the Maritime Alps is $132 \mathrm{~mm} /$ day. Few members predict maximum amounts slightly larger than $200 \mathrm{~mm} /$ day.

\subsection{Ensemble spread as an index of predictability}

The ensemble spread is a measure of the variability between the members, and it is represented by the standard deviation with respect to the ensemble mean. In the theoretical case in which the ensemble mean perfectly matches the observations, high spread would indicate low forecast predictability, while small spread would indicate good forecast predictability. In the
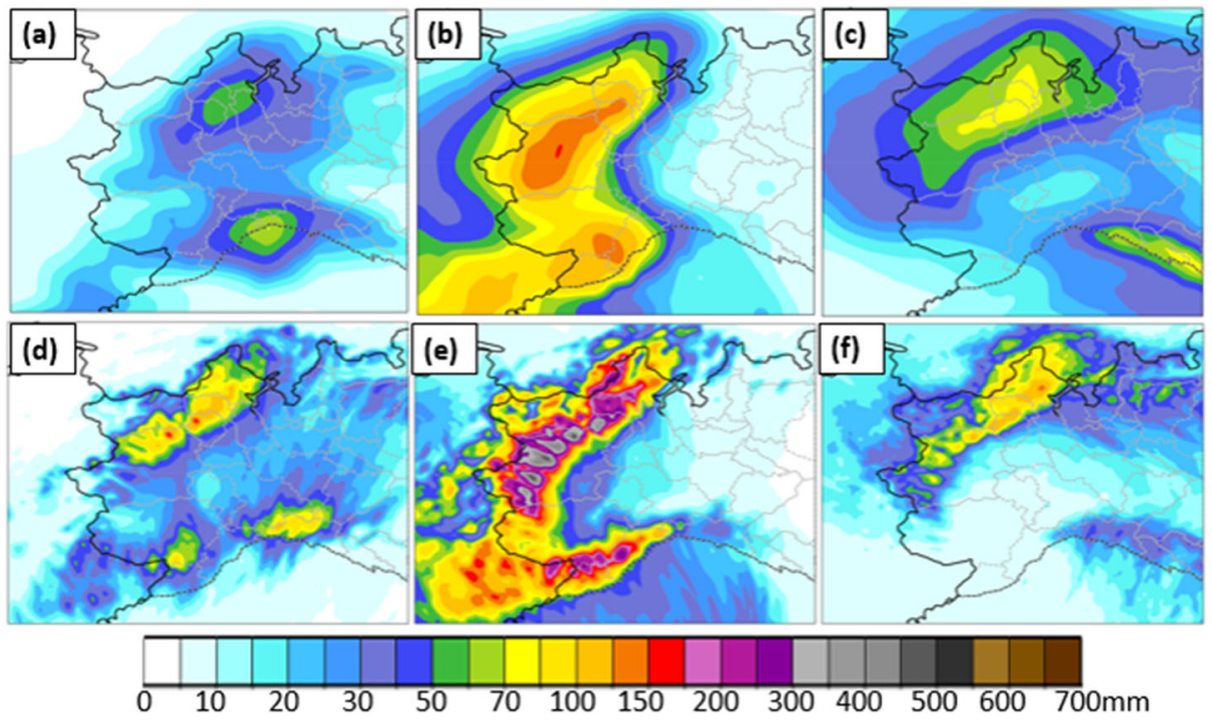

Fig. 9 Ensemble mean, maps of daily accumulated precipitations for 4 November (a, d), 5 November (b, e), and 6 November 1994 (c, f); the first line (a, b, c) refers to ECMWF ENS forecasts, the second (d, e, f) to COSMO2I-EPS ones 
real cases, the ensemble mean has an error and the ratio between its skill and the spread is commonly used to statistically validate the ability of the ensemble system to represent the full uncertainty range as realistically as possible. From the point of view of the forecaster, who does not know yet the skill of the forecast, the spatial distribution of spread can be a powerful instrument in combination with the ensemble mean to point out the regions of low/high predictability of the EPS, which hopefully resembles the areas characterized by small/large ensemble error.

On 4 November, COSMO-2I-EPS presents in general low spread over the Piedmont region aside from a nucleus of high spread (maximum $68 \mathrm{~mm} /$ day) over Genova Province, in the central sector of Ligurian Apennines (Fig. 10(d)). In this small area, the ensemble spread has about the same order of magnitude of the ensemble mean, thus indicating that very different scenarios are foreseen (either no precipitation or more precipitation than the mean). A few ensemble members predict the development of a V-shaped regenerating thunderstorm, with a total amount of precipitation above $300 \mathrm{~mm}$. A very intense convective system $(135 \mathrm{~mm}$ of precipitation in $4 \mathrm{~h}$ ) was indeed observed in Savona hinterland, about $40 \mathrm{~km}$ west of the location where COSMO-2I-EPS predicted the most intense precipitations. Convective systems of this kind are very difficult to predict, but can be extremely dangerous, and have caused severe damages in different occasions in Liguria. Since they are very localized, and only two stations were available in Genova Province, it cannot be excluded that other intense convective systems developed in the area; anyhow, the very high ensemble spread could at least hint to the forecasters that dangerous storms may occur in central Liguria. On the other hand, the coarseresolution ensemble system EPS predicts a broad precipitation pattern, and the ensemble spread is about $30 \%$ of the ensemble mean, thus giving little indication that intense phenomena could occur. On 5 November (Fig. 10(e)), some spread is presented over the Ligurian Sea, associated with the uncertainty in the velocity of the shift towards the east of the warm
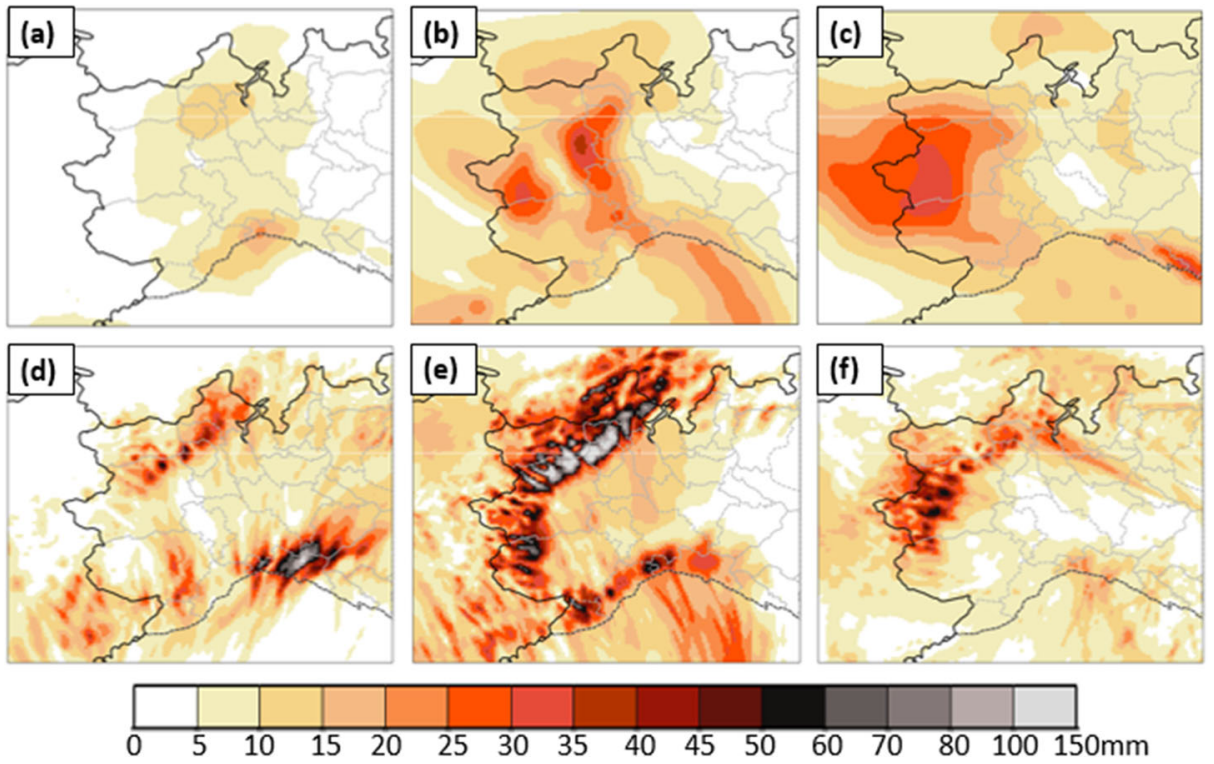

Fig. 10 Ensemble spread of daily accumulated precipitations for 4 November (a, d), 5 November (b, e), and 6 November 1994 (c, f); the first line (a, b, c) refers to ECMWF ENS forecasts, the second (d, e, f) to COSMO-2IEPS ones 
conveyor belt. The same source of uncertainty motivates also the spread in the areas where the orographic lift of warm humid air triggers the convective precipitation, i.e., over the Ligurian Apennines and over the northern sector of Piedmont Alps. In practice, COSMO-2I-EPS is uncertain in positioning further east or west convection areas when the flow impacts on the mountains. Lower spread values are reported over the western sector of the Alps, where the ensemble mean locates the maximum amounts of accumulated precipitation. Here, the flow is directed towards the northwest for the entire day, independently of the position of the prefrontal system. The correlation of the ensemble mean and spread with the model orography is of interest (Fig. 11). The ensemble mean indicates that on the western Alps the heaviest precipitation falls at the first impact of the air mass against the mountains, in particular on the orography uphill at an altitude between approximately 800 and $2000 \mathrm{~m}$. Therefore, according to COSMO-2I-EPS, it is highly predictable that in these mountainsides the air mass has enough energy to rise and flow over, with the consequent condensation and precipitation. Regarding the ensemble spread, its spatial pattern is very variable and it follows the complex orography. In some cases, high uncertainty is located in the valleys, expressing low predictability in defining the tendency of airflow to flank the orography and condensate in the valley. In other cases, the spread is large in correspondence with the slope updraft, which indicates uncertainty in the amount of the convective precipitation component triggered by orographic uplift. The "flow over" or "flow around" tendencies are determined by the static stability of the incoming air mass (including the latent heat release in case of saturated uplift), expressed by Brunt Waisala frequency $N$, in relation to the low-level horizontal wind $U$ and the mountain height $H$. These factors are combined in the Froude number $\mathrm{Fr}=U /(N H)$. In case of $\mathrm{Fr}>>1$, the updraft motion is favored, while values of $\mathrm{Fr}<<1$ are connected with the occurrence of upstream blocking and air flanking. As argued by Buzzi et al. (1998), given the conditions of air saturation during this event, a Fr $>>1$ would be easily reached in the western Alps (considering $H=3000 \mathrm{~m}$ and $U=10 \mathrm{~m} / \mathrm{s}$ ) and consequently the lift of air upstream the orography. However, this mechanism that acts on the scales of tens of kilometers can be influenced and locally modified by the peculiarities of the complex orography (e.g., mountain
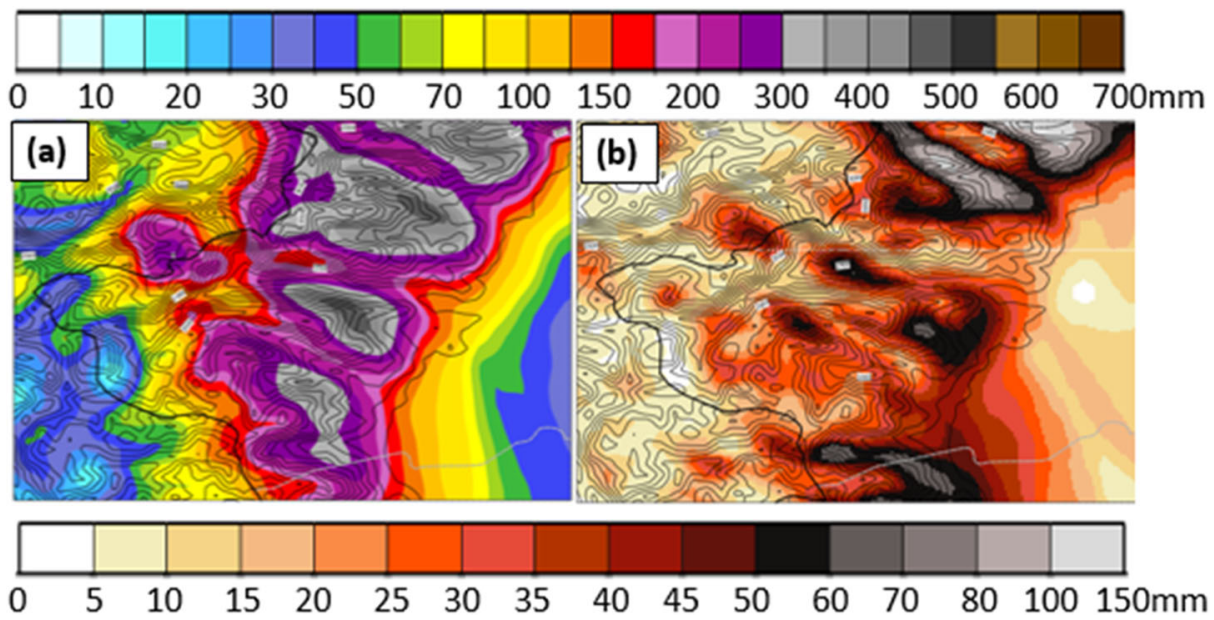

Fig. 11 Ensemble mean (a) and ensemble spread (b) of total precipitation for 5 November 1994 as forecast by COSMO-2I-EPS; in the maps, the orography was superimposed to study its effect on the uncertainty in distribution and intensity of precipitation 
geometry, valley entrance and axis, etc.) and by local and temporary variations in the air mass properties (wind direction and intensity, local vortex, etc.). Kilometer-scale models, allowing the explicit representation of deep convection, have the possibility to reproduce in part these small-scale interactions. The spread generated by COSMO-2I-EPS in the western Alps well depicts the model uncertainty at this level, due to the member-by-member varying interaction between the orography and the air mass thermodynamic energy.

The same processes extend during the first hours of the 6th of November, before the cold front passage, yielding to the largest part of the daily spread over the western sector of the Piedmont Alps (Fig. 10(f)).

It is of interest to compare the ensemble mean with the ensemble spread in the ENS case with respect to COSMO-2I-EPS (Figs. 9 and 10). The spatial pattern of both mean and spread is obviously smoother in ENS than in COSMO-based EPS, due to the coarser resolution of the former. In both systems, ensemble members disagree on the precise location of the most intense precipitations, leading to higher uncertainty near the edges of the intense precipitation areas. In ENS, the displacement between members is relatively large, indicating that intense precipitations could affect most of the Piemonte flat and hill areas. Conversely, in COSMO-2IEPS, the pattern of uncertainty is very similar to that of the average precipitation, since ensemble members consistently concentrate precipitation in mountainous regions: uncertainty is high, but it mostly affects the smaller scales.

\subsection{Study of the temporal and spatial trend of precipitation}

The probabilistic forecast of the flood event is analyzed in three locations in correspondence with a rain gauge station, considering the EPS forecasts initialized on 3 November at 00 UTC. Since these observations are not exactly located at the ensemble system grid points, the observed values are compared with those predicted at the nearest grid points.

The three considered sites are located on the areas mostly affected by heavy precipitation, respectively on the Maritime Alps (Garessio, Cuneo Province), on the northeast sector of the Piedmont Alps (Trontano, Verbania Province), and on the northwest sector of the Alps (Lanzo Torinese, Torino Province) (Fig. 12). Note that, while Garessio and Trontano are located above $1000 \mathrm{~m}$ within the Alpine chain, Lanzo station is at $590 \mathrm{~m}$ of altitude, at the entrance of a mountain valley. Therefore, the three selected stations represent different precipitation patterns and temporal trends of the event.

The rain gauge in Garessio recorded the largest accumulated amount of rainfall during the flood over the Maritime Alps. On 4 November, the time series recorded the passage of the prefrontal system (at time range $+36 \mathrm{~h}$ ) with a secondary maximum $(14.6 \mathrm{~mm}$ in $6 \mathrm{~h}$ ). The precipitation intensity was maximum on 5 November between 0 UTC and 18 UTC (accumulated amount of $88.8 \mathrm{~mm}$ in $6 \mathrm{~h}$ ), in correspondence with the intensification of the southerly flow into the orographic barrier, and finally, it ceased on 6 November, when the southerly flow interrupted.

The ensemble mean of COSMO-2I-EPS represents rather well the observed temporal evolution, and, respectively, the secondary and main precipitation peaks are correctly simulated at forecast ranges $+36 \mathrm{~h}$ and $+60 \mathrm{~h}$. The temporal evolution of precipitation in ECMWF ENS is less satisfactory, since the ensemble mean indicates a single precipitation peak, six hours later than the observations. Both systems underestimate the total rainfall and the peak rain rates; nevertheless, the observed values are within the range of COSMO-2I-EPS members.

According to observations, on 5 November, precipitations were more intense on the northern (leeward) flank of Maritime Alps (Fig. 4, middle). In this respect, the comparison 

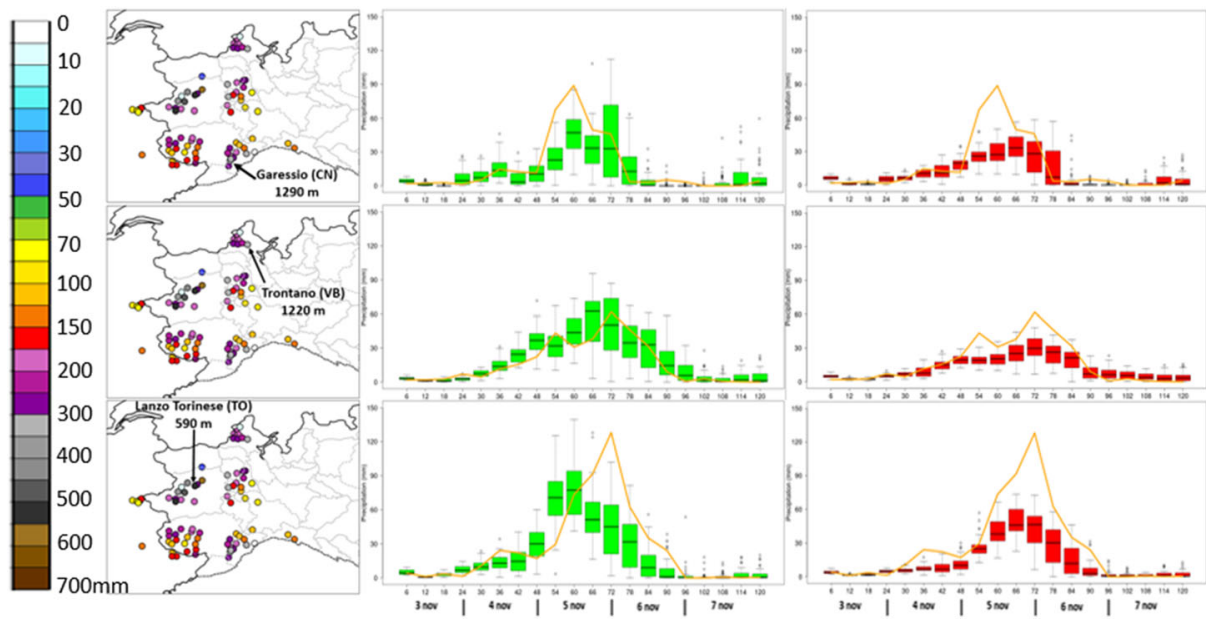

Fig. 12 Meteograms for the precipitation forecasted by COSMO-2I-EPS (green) and by ENS (red). The superimposed orange line is the observed precipitation with accumulation steps of $6 \mathrm{~h}$ at the station. The data are extrapolated for 3 stations of the Arpa Piemonte network considered relevant for the amount of precipitation and geographical location: Garessio (top), Trontano (center), and Lanzo Torinese (bottom)

of the two ensemble systems is not straightforward since they use a different topography, but COSMO-2I-EPS seems nonetheless to perform better than ECMWF ENS: in the former, precipitation is evenly distributed in the north and south catchments, while the latter predicts that about two thirds of precipitation will fall in the southern flank of Maritime Alps.

The ensemble spread is particularly high at forecast range $+72 \mathrm{~h}$, due to the temporal uncertainty in the suspension of the southerly wind over this area. The same uncertainty is reported also by the ECMWF ensemble, confirming that it originates from large-scale processes.

At Trontano station, the time series presents two peaks, respectively on 4 and 6 November, because on 5 November, the orographic lift affected less the northeast sector of the Piedmont Alps. The COSMO-based EPS is well in agreement with the recorded time trend, and the observations fall in the PDF interquartile almost at every time range.

Finally, at Lanzo Torinese, the surface observations report a temporal evolution similar to Garessio, with a higher peak of rainfall intensity on 5 November $(128.2 \mathrm{~mm}$ accumulated in $6 \mathrm{~h})$. COSMO-2I-EPS correctly forecasts the increment of precipitation on 5 November, despite underestimating the heaviest amounts, as noted in the Garessio case (also, here, the ensemble tail reports values similar to the observations). It is remarked that COSMO-2I-EPS shows the rainfall peak $12 \mathrm{~h}$ in advance compared to the record. This temporal mismatch is not visible in other stations sited in the same Alpine sector (not shown), and it is associated with the specific location of Lanzo Torinese at a valley entrance. As reviewed in Section 3.3, COSMO-2I-EPS presents the largest spread in the orographic inflow and in the valleys, due to the small-scale interaction between the complex terrain and the air mass. In the Lanzo Torinese case, the uncertainty due to these small-scale processes is reflected in this temporal drift.

In conclusion, the meteogram analysis shows that COSMO-2I-EPS has a higher agreement with the observed amounts of precipitation accumulated in $6 \mathrm{~h}$ compared to ENS, with the surface records falling within the range of COSMO-2I-EPS members almost in all cases. However, the temporal evolution is not always in line with the records, due to the imprecise representation of local scale processes (e.g., for the case observed at Lanzo Torinese station). Vice versa, the ECMWF ensemble shows a temporal evolution of the precipitation in fair 
agreement with the observed rainfall rate, but it evidences a large underestimation of the observations for values larger than $30 \mathrm{~mm}$ accumulated in $6 \mathrm{~h}$, as expected consequence of the coarse resolution.

\section{Conclusions}

After 25 years, the major flood that occurred in November 1994 in the Piedmont region of northern Italy has been re-forecast using a convection-allowing ensemble system. The configuration is set similarly to those of COSMO-2I-EPS, the ensemble system based on the limited area model COSMO at $2.2 \mathrm{~km}$ of horizontal resolution, which is pre-operational at ARPAESIMC at the time of writing. The COSMO-2I-EPS experiment has been driven by a global reforecast performed by ECMWF using the EPS system updated at the IFS cycle 46r1, also operational at the time of writing.

During this major flood, the nature and position of precipitation were mainly driven by large-scale features, such as the transit of the warm conveyor belt, the thermodynamic characteristics of the air mass, the intensity of the southerly flow, and the divergence at upper tropospheric layers. Small-scale processes, such as the complex interaction between topography and convective systems, had nonetheless a major influence on the details of the precipitation pattern, especially in southern Piemonte, where the greatest damages were reported.

On the whole, ECMWF ENS forecast is rather good: the areas affected by heavy rainfall, as well as the temporal evolution of the event, are in broad agreement with observations; nevertheless, the total amount of precipitation is underestimated, and the model fails to reproduce some important features of the spatial distribution.

COSMO-2I-EPS, thanks to the explicit convection and the high-resolution topography, can better reproduce the precipitation peaks and small-scale features of the event.

The moderate stratiform precipitation diffused over the Piedmont region has been correctly forecast with high confidence more than two days in advance by both systems. The intense precipitation that affected the northwest sector of the Alps and the Maritime Alps has been correctly located by both EPS, although COSMO-2I-EPS presented a higher agreement with the observations with a larger confidence level. The advantage of high resolution resulted particularly evident in predicting very intense precipitation (more than 150 and $200 \mathrm{~mm}$ in $24 \mathrm{~h}$ ), which affected several spots in the Piedmont Alps during this event. Indeed, while the global EPS showed a low or no probability of occurrence, COSMO-2I-EPS presented a probability of occurrence greater than $90 \%$ over extended mountain areas in very good agreement with the available observations. A second positive impact of the convection-permitting resolution was the improvement of the location of the orographic precipitation on the mountain uphill, reducing the upstream precipitation displacement produced by the ECMWF ensemble.

The link between the ensemble spread and the predictability has been considered for the two systems. In COSMO-2I-EPS, the patterns of the ensemble spread and mean resulted similar, since the members consistently concentrated precipitation in mountainous regions. Here, the uncertainty has been associated to the flow interaction with the smaller-scale orography characteristics affecting small scales as well. It has also been shown as the spread of COSMO-2I-EPS can give useful indications on the possible occurrence of strong and localized convective systems, which may not be predictable in detail. Nevertheless, the development of a methodology capable of quantifying the link between spread and predictability for operational purposes is still a matter of research. 
As a general remark, although it is just a case study, this work shows great advancements in terms of probabilistic forecast compared to the ensemble products available at the time of the Piedmont flood, namely the global ensemble of ECMWF at a horizontal resolution of $320 \mathrm{~km}$, and compared to the early limited area probabilistic products, developed some years later. Modern convection-permitting ensemble systems have significantly increased the capacity in predicting extreme weather events, as already many publications have widely shown (e.g., Tibaldi et al. 2006; Lalaurette and van der Grijn 2009; Swinbank et al. 2016; Mylne 2002; Petroliagis et al. 1997). These performance improvements can mainly be defined in terms of confidence of occurrence and the identification of affected areas; also, thanks to the superior representation of those small-scale processes that are pivotal over complex orography. In this sense, early warning systems based on the convection-permitting ensemble can be considered a major step forward in the direction of having a reliable forecasting support also in case of extreme and dangerous events such as the major Piedmont flood of 1994. Nonetheless, while state-of-the-art prediction systems can be trustworthy in large-scale-driven events such as the Piedmont flood, severe convective events of isolated nature triggered by small-scale processes (e.g., regenerating thunderstorms) are still a challenge to predict even a few hours in advance.

To date, for this type of rapidly evolving and severe convective events, numerous studies have been and are being carried out to improve forecasting with a focus on very-short-term prediction. Both an increase in the resolution of improved forecast models and the new assimilation techniques allowing the use of high-density data (e.g., radar, satellite) allow the production of frequent rapid update cycles (RUC), very short-term forecasting applications.

These new techniques can, however, produce an improvement even in cases such as that of Piedmont 1994. Increasing the predictability of the extreme convection embedded in the largescale structure is extremely important and useful for focusing alert actions as the event approaches.

Open Access This article is licensed under a Creative Commons Attribution 4.0 International License, which permits use, sharing, adaptation, distribution and reproduction in any medium or format, as long as you give appropriate credit to the original author(s) and the source, provide a link to the Creative Commons licence, and indicate if changes were made. The images or other third party material in this article are included in the article's Creative Commons licence, unless indicated otherwise in a credit line to the material. If material is not included in the article's Creative Commons licence and your intended use is not permitted by statutory regulation or exceeds the permitted use, you will need to obtain permission directly from the copyright holder. To view a copy of this licence, visit http://creativecommons.org/licenses/by/4.0/.

\section{References}

Atencia A, Rigo T, Sairouni A, Moré J, Bech J, Vilaclara E, Cunillera J, Llasat MC, Garrote L (2010) Improving QPF by blending techniques at the Meteorological Service of Catalonia. Nat Hazards Earth Syst Sci 10: 1443-1455. https://doi.org/10.5194/nhess-10-1443-2010

Bechtold P, Semane N, Lopez P, Chaboureau J-P, Beljaars A, Bormann N (2014) Representing equilibrium and non-equilibrium convection in large-scale models. J Atmos Sci 71:734-753

Bonavita M, Torrisi L, Marcucci F (2010) Ensemble data assimilation with the CNMCA regional forecasting system. Q J Roy Meteor Soc 136:132-145. https://doi.org/10.1002/qj.553

Bouttier F, Vié B, Nuissier O, Raynaud L (2012) Impact of stochastic physics in a convection-permitting ensemble. Mon Weather Rev 140:3706-3721. https://doi.org/10.1175/MWR-D-12-00031.1

Bowler NE, Pierce CE, Seed AW (2006) STEPS: a probabilistic precipitation forecasting scheme which merges an extrapolation nowcast with downscaled NWP. QJR Meteorol Soc 132:2127-2155. https://doi.org/10. 1256/qj.04.100 
Buizza R, Miller M, Palmer TN (1999) Stochastic representation of model uncertainties in the ECMWF ensemble prediction system. Q J R Meteorol Soc 125:2887-2908

Buzzi A, Tartaglione N, Malguzzi P (1998) Numerical simulations of the 1994 Piedmont flood: role of orography and moist processes. Mon Weather Rev 126:2369-2383. https://doi.org/10.1175/1520-0493(1998) $126<2369$ :NSOTPF $>2.0 . \mathrm{CO} ; 2$

Cassardo C, Loglisci N, Gandini D, Qian MW, Niu GY, Ramieri P, Pelosini R, Longhetto A (2002) The flood of November 1994 in Piedmont, Italy: a quantitative analysis and simulation. Hydrol Process 16:1275-1299. https://doi.org/10.1002/hyp.1062

Chappell CF (1986) Quasi-stationary convective events. In: Ray PS (ed) Mesoscale meteorology and forecasting, Am Meteorol Soc., pp 289-310

Clark AJ, Gallus WA, Xue M, Kong F (2010) Growth of spread in convection-allowing and convectionparameterizing ensembles. Wea Forecasting 25:594-612. https://doi.org/10.1175/2009WAF2222318.1

Delrieu G, Nicol J, Yates E, Kirstetter P-E, Creutin J-D, Anquetin S, Obled C, Saulnier G-M (2005) The catastrophic flash-flood event of 8-9 September 2002 in the Gard Region, France: a first case study for the Cévennes-Vivarais Mediterranean Hydrometeorological Observatory. J Hydrometeorol 6:34-52

Ferraris L, Rudari R, Siccardi F (2002) The uncertainty in the prediction of flash floods in the northern Mediterranean environment. J Hydrometeorol 3:714-727. https://doi.org/10.1175/1525-7541(2002) 003<0714:TUITPO >2.0.CO;2

Fiori E, Comellas A, Molini L, Rebora N, Siccardi F, Gochis DJ, Tanelli S, Parodi A (2014) Analysis and hindcast simulations of an extreme rainfall event in the Mediterranean area: the Genoa 2011 case. Atmos Res 138(2014):13-29. https://doi.org/10.1016/j.atmosres.2013.10.007

Frogner I-L, Singleton AT, Køltzow MØ, Andrae U (2019) Convection-permitting ensembles: challenges related to their design and use. Q J R Meteorol Soc 145(Suppl. 1):90-106. https://doi.org/10.1002/qj.3525

Gastaldo T, Poli V, Marsigli C, Alberoni PP, Paccagnella T (2018) Data assimilation of radar reflectivity volumes in a LETKF scheme. Nonlinear Process Geophys 25:747-764. https://doi.org/10.5194/npg-25$747-2018$

Golding B (1998) Nimrod: a system for generating automated very short range forecasts. Meteorol Appl 5:1-16

Haiden T, Kann A, Wittmann C, Pistotnik G, Bica B, Gruber C (2011) The Integrated Nowcasting through Comprehensive Analysis (INCA) system and its validation over the eastern Alpine region. Wea Forecasting 26:166-183. https://doi.org/10.1175/2010WAF2222451.1

Hagelin S, Son J, Swinbank R, McCabe A, Roberts N, Tennant W (2017) The Met Office convective scale ensemble, MOGREPS-UK. QJR Meteorol Soc 143:2846-2861. https://doi.org/10.1002/qj.3135

Hersbach H, Bell B, Berrisford P et al (2020) The ERA5 global reanalysis. Q J R Meteorol Soc 146:1999-2049. https://doi.org/10.1002/qj.3803

Hohenegger C, Walser A, Langhans W, Schär C (2008) Cloud-resolving ensemble simulations of the August 2005 Alpine flood. QJR Meteorol Soc 134:889-904. https://doi.org/10.1002/qj.252

Iyer ER, Clark AJ, Xue M, Kong F (2016) A comparison of 36-60-h precipitation forecasts from convectionallowing and convection-parameterizing ensembles. Wea Forecasting 31:647-661. https://oi.org/10.1175/ WAF-D-15-0143.1

Klasa C, Arpagaus M, Walser A, Wernli H (2018) An evaluation of the convection-permitting ensemble COSMO-E for three contrasting precipitation events in Switzerland. Q J R Meteorol Soc 144:744-764. https://doi.org/10.1002/qj.3245

Lalaurette F, van der Grijn G (2009) Ensemble forecasts: can they provide useful early warnings? Publisher, Cambridge University Press, pp 614-627. https://doi.org/10.1017/CBO9780511617652.025

Le Duc, Saito K, Seko H (2013) Spatial-temporal fractions verification for high-resolution ensemble forecasts. Tellus A 65:1. https://doi.org/10.3402/tellusa.v65i0.18171

Leutbecher M, Lock S-J, Ollinaho P, Lang STK, Balsamo G, Bechtold P, Bonavita M, Christensen HM, Diamantakis M, Dutra E, English S, Fisher M, Forbes RM, Goddard J, Haiden T, Hogan RJ, Juricke S, Lawrence H, MacLeod D, Magnusson L, Malardel S, Massart S, Sandu I, Smolarkiewicz PK, Subramanian A, Vitart F, Wedi N, Weisheimer A (2017) Stochastic representations of model uncertainties at ECMWF: state of the art and future vision. QJR Meteorol Soc 143:2315-2339. https://doi.org/10.1002/qj.3094

Luino F (1999) The flood and landslide event of November 4-6 1994 in Piedmont region (northwestern Italy): causes and related effects in Tanaro Valley. Phys Chem Earth Solid Earth Geod 24(2):123-129, ISSN 14641895. https://doi.org/10.1016/S1464-1895(99)00007-1

Marcucci F, Torrisi L, Sebastianelli S (2014) Status of COSMO-ME-EPS system. In: Conference: 16th COSMO General Meeting. http://www.cosmo-model.org/content/consortium/generalMeetings/general2014/wg1kenda/meEps_torrisi.pdf

Marsigli C, Montani A, Nerozzi F, Paccagnella T, Tibaldi S, Molteni F, Buizza R (2001) A strategy for highresolution ensemble prediction. II: limited-area experiments in four Alpine flood events. QJR Meteorol Soc 127:2095-2115. https://doi.org/10.1002/qj.49712757613 
Marsigli C(2020) On the initial conditions of the ICON-D2-EPS ensemble: an analysis in terms of spread and skill. EGU General Assembly 2020, Online, 4-8 May 2020, EGU2020-10803, https://doi.org/10.5194/ egusphere-egu2020-10803

Molteni F, Buizza R, Palmer TN, Petroliagis T (1996) The ECMWF ensemble prediction system: methodology and validation. QJR Meteorol Soc 122:73-119. https://doi.org/10.1002/qj.49712252905

Montani A, Marsigli C, Nerozzi F, Paccagnella T, Buizza R (2001) Performance of the ARPA-SMR limited-area ensemble prediction system: two flood cases. Nonlin Processes Geophys 8:387-399. https://doi.org/10.5194/ npg-8-387-2001

Montani A, Marsigli C, Nerozzi F, Paccagnella T, Tibaldi S, Buizza R (2003) The Soverato flood in southern Italy: performance of global and limited-area ensemble forecasts. Nonlin Processes Geophys 10:261-274. https://doi.org/10.5194/npg-10-261-2003

Mylne KR (2002) Decision-making from probability forecasts based on forecast value. Met Apps 9:307315. https://doi.org/10.1017/S1350482702003043

Nerini D, Foresti L, Leuenberger D, Sylvain R, Germann U (2019) A reduced-space ensemble Kalman filter approach for flow-dependent integration of radar extrapolation Nowcasts and NWP precipitation ensembles. Mon Weather Rev 147:987-1006. https://doi.org/10.1175/MWR-D-18-0258.1

Palmer T (2019) The ECMWF ensemble prediction system: looking back (more than) 25 years and projecting forward 25 years. Q J R Meteorol Soc 145 (Suppl. 1):12-24. https://doi.org/10.1002/qj.3383

Petroliagis T, Buizza R, Lanzinger A, Palmer T (1997) Potential use of the ECMWF ensemble prediction system in cases of extreme weather events. Meteorol Appl 4(1):69-84. https://doi.org/10.1017/ S1350482797000297

Pierce C, Hardaker P, Collier C, Haggett C (2001) GANDOLF: a system for generating automated nowcasts of convective precipitation. Meteorol Appl 7:341-360

Ricard D, Ducrocq V, Auger L (2012) A climatology of the mesoscale environment associated with heavily precipitating events over a northwestern Mediterranean area. J Appl Meteorol Climatol 51:468-488. https:// doi.org/10.1175/JAMC-D-11-017.1

Richard E, Buzzi A, Zängl G (2007) Quantitative precipitation forecasting in the Alps: the advances achieved by the Mesoscale Alpine Programme. QJR Meteorol Soc 133:831-846. https://doi.org/10.1002/qj.65

Schaettler U, Doms G, Schraff C (2019) A description of the nonhydrostatic regional COSMO-model part VII: user's guide. Consortium for Small-Scale Modelling. https://doi.org/10.5676/dwd_pub/nwv/cosmo-doc_5. 06 VII

Schraff C, Reich H, Rhodin A, Schomburg A, Stephan K, Periáñez A, Potthast R (2016) Kilometre-scale ensemble data assimilation for the COSMO model (KENDA). QJR Meteorol Soc 142:1453-1472. https:// doi.org/10.1002/qj.2748

Smith SA, Vosper SB, Field PR (2015) Sensitivity of orographic precipitation enhancement to horizontal resolution in the operational Met Office weather forecasts. Met Apps 22:14-24. https://doi.org/10.1002/ met.1352

Surcel M, Zawadzki I, Yau MK (2015) A study on the scale dependence of the predictability of precipitation patterns. J Atmos Sci 72:216-235. https://doi.org/10.1175/JAS-D-14-0071.1

Swinbank R, Friederichs P, Wahl S (2016) Forecasting high-impact weather using ensemble predictions systems. Cambridge University press, pp 95-112, https://doi.org/10.1017/CBO9781107775541.008

Tibaldi S, D’Andrea F, Tosi E, Roeckner E (1997) Climatology of northern hemisphere blocking in the ECHAM model. Clim Dyn 13:649-666. https://doi.org/10.1007/s003820050188

Tibaldi S, Paccagnella T, Marsigli C, Montani A, Nerozzi F (2006) Limited-area ensemble forecasting: the COSMO-LEPS system. In: Palmer T, Hagedorn R (eds) Predictability of weather and climate. Cambridge University Press, Cambridge, pp 489-513. https://doi.org/10.1017/CBO9780511617652.019

Vitart F, Balsamo G, Bidlot J-R, Lang S, Tsonevsky I, Richardson D, Balmaseda M (2009) Use of ERA5 reanalysis to initialise re-forecasts proves beneficial. ECMWF Newsletter 161:26-31. https://doi.org/10. 21957/g71fv083lm

Wong W, Yeung L, Wang Y, Chen M (2009) Towards the blending of NWP with Nowcast-operation experience in B08FDP. WMO symposium on Nowcasting, vol. 30 